\title{
VARIABILIDADE ESPACIAL DA FERTILIDADE DE NEOSSOLO QUARTZARÊNICO EM FUNÇÃO DA SUBSTITUIÇÃO DO CERRADO POR PASTAGEM
}

\author{
Sabino Pereira da Silva Neto ${ }^{1}$, Antonio Clementino dos Santos ${ }^{2}$, José Expedito Cavalcante da Silva ${ }^{3}$
}

\section{RESUMO}

As características químicas dos solos do Cerrado brasileiro são facilmente alteradas pelas intervenções humanas. O objetivo desse estudo foi avaliar a variabilidade espacial das propriedades químicas em um Neossolo Quartzarênico Órtico típico, em função da substituição do Cerrado por Pastagem, na região de Araguaína (TO), Brasil. Foram feitas amostragens do solo em uma malha irregular em área de 13,11 ha, na profundidade de $0 \mathrm{a} 20 \mathrm{~cm}$, para determinação dos teores de matéria orgânica (MO), $\mathrm{Al}^{3+}, \mathrm{P}, \mathrm{K}^{+}, \mathrm{Ca}^{2+}, \mathrm{Mg}^{2+}$, valores de $\mathrm{pH}$, soma de bases (SB), capacidade de troca de cátions em pH 7,0 $\left(\mathrm{CTC}_{\mathrm{pH} 7}\right)$, capacidade de troca de cátions efetiva $\left(\mathrm{CTC}_{\mathrm{e}}\right)$, saturação por bases - $\mathrm{V} \%$ e saturação por alumínio - $\mathrm{m} \%$. As propriedades químicas do solo foram analisadas por estatística descritiva e tiveram suas médias comparadas pelo teste de Tukey, a 5\% probabilidade, utilizando geoestatístico e interpolação por krigagem ordinária. Os alcances de dependência espacial dos atributos químicos $\mathrm{pHe} \mathrm{Ca}^{2+}$ do solo foram menores que os demais ( $\mathrm{MO}, \mathrm{Al}^{3+}, \mathrm{P}, \mathrm{K}^{+}, \mathrm{Mg}^{2+}, \mathrm{SB}, \mathrm{CTC}_{\mathrm{pH}}, \mathrm{CTC}_{\mathrm{e}} \mathrm{e} \mathrm{V \%}$ ), indicando que eles apresentam menor continuidade na distribuição espacial em Neossolo Quartzarênico Órtico típico, em função da conversão do Cerrado em Pastagem.

Palavras-chave: Análise espacial, geoestatística, krigagem, manejo do solo, variograma

\section{ABSTRACT \\ SPATIAL VARIABILITY OF FERTILITY ATTRIBUTES IN A ENTISOL TYPIC THROUGH THE REPLACEMENT OF THE CERRADO FOR GRASSLAND}

The chemical characteristics of soils in the Brazilian Cerrado are easily changed by human interventions. The aim of this study was to evaluate the spatial variability of chemical properties in Entisol Typic due to Cerrado cleaning substited by pasture in the region of Araguaina (TO), Brazil. Samples were taken in an irregular grid in an area of $13.11 \mathrm{ha}$, in the depth of 0 to $20 \mathrm{~cm}$, to determine the levels of organic matter (OM), $\mathrm{Al}^{1+}, \mathrm{P} \mathrm{K}^{+}, \mathrm{Ca}^{2+}, \mathrm{Mg}^{2+}$ and $\mathrm{pH}$ values, sum of bases $(\mathrm{SB})$, capacity cation exchange to $\mathrm{pH} 7.0\left(\mathrm{CEC}_{\mathrm{pH}}\right.$ ), ability to effective cation exchange (CECe), base saturation (V\%) and aluminum saturation $(\mathrm{m} \%)$. The soil chemical properties were analyzed using descriptive statistics and had average compared by the Tukey test, at $5 \%$ probability, using geostatistics and interpolated by ordinary kriging. The ranges of spatial dependence of the chemical variables $\mathrm{pH}$ and $\mathrm{Ca}^{2+}$ in the soil were lower than the others $\left(\mathrm{OM}, \mathrm{Al}^{3+}, \mathrm{P}, \mathrm{K}^{+}, \mathrm{Mg}^{2+}, \mathrm{SB}, \mathrm{CTC}_{\mathrm{pH}}\right.$,, $\mathrm{CECe}$ and $\left.\mathrm{V} \%\right)$, indicating that they have a smaller continuity in the spatial distribution in Entisol Typic depending on the conversion of the Cerrado grasslands.

Keywords:, Geostatistics, ordinary kriging, soil management, spatial analysis, variogram.

Recebido para publicação em 18/01/2010. Aprovado em 19/04/2011.

1-Zootecnista, Doutorando em Ciência Animal Tropical - UFT, Araguaína - TO, e-mail: sabinozootec@yahoo.com.br

2- Eng. Agrônomo, DSc, Prof. do Programa de pós-graduação em Ciência Animal Tropical-UFT, Araguaína-TO, e-mail: clementino@uft.edu.br

3- Bacharel em Química, DSc, Prof. do Programa de pós-graduação em Ciência Animal Tropical - UFT, Araguaína - TO, e-mail: jecs@uft.edu.br

334 REVENG

334-347 p. ENGenharia NA Agricultura, VIÇOSA - MG, V.19 N.4, JULHO / AGOSTO 2011 


\section{INTRODUÇÃO}

O bioma Cerrado ocupa aproximadamente um quarto de todo o território nacional e vem passando por mudanças causadas principalmente pelas atividades de criação de gado e de expansão da área agrícola. Neste bioma, os solos são naturalmente ácidos devido à composição do seu material de origem e elevado processo de intemperismo, normalmente apresentando baixos valores de $\mathrm{pH}$ (potencial hidrogeniônico), elevados teores de alumínio trocável e baixos teores de cálcio $\left(\mathrm{Ca}^{2+}\right)$ e magnésio $\left(\mathrm{Mg}^{2+}\right)$, características limitantes ao desenvolvimento vegetal.

A região de Araguaína (TO) tem como principal classe de solo os Neossolos Quartzarênicos, que ocupam $41,10 \%$ do território dessa região (EMBRAPA, 2005). Em geral, esses solos são originados de depósitos arenosos, apresentando textura areia ou areia franca ao longo de pelo menos dois metros de profundidade, com quantidade de argila menor que $15 \%$. São constituídos, essencialmente, de grãos de quartzo resistentes ao intemperismo, e, por conseguinte, praticamente destituídos de minerais primários. São considerados de baixa aptidão agrícola e o uso continuado com culturas anuais pode levá-los rapidamente à degradação. São solos com baixa capacidade de agregação de partículas, baixos teores de argilas e de matéria orgânica e possuem baixa capacidade de retenção de água (EMBRAPA, 2006).

Apesar da baixa aptidão agrícola desses solos, grandes áreas de Cerrado nativo foram convertidas em pastagens nessa região, por meio de derrubada e/ou queimada da vegetação natural. Diferentes práticas e sistemas de manejo levam à redução da fertilidade do solo (BERNOUX et al., 2004) e a aumentos nos custo de produção e manutenção do sistema produtivo após poucos anos de uso. Essas áreas de pastagem, posteriormente, são abandonadas, ou não são adotadas práticas de manejo da fertilidade do solo, o que não permite a manutenção da produtividade. Normalmente, essas pastagens apresentam reduzida capacidade de ciclagem de nutrientes (OLIVEIRA et al., 2004; SOUZA et al., 2008; VOLPE et al., 2008).

O uso do solo, com o passar do tempo, conduz ao aumento na heterogeneidade dos atributos físicos, químicos e biológicos, por meio dos processos de desmatamento, preparo do solo, rotações de cultura e localização de aplicação de fertilizantes (CAVALCANTE et al., 2007). Por isso, tanto a variabilidade espacial quanto a temporal dos atributos do solo devem ser incorporadas aos procedimentos e tecnologias aplicados à agricultura (LI et al., 2002). De acordo com Vieira (2000), a variabilidade espacial das propriedades do solo vem sendo uma das preocupações de pesquisadores, praticamente desde o início do século.

A análise espacial dos atributos da fertilidade pode melhorar a eficiência da aplicação de corretivos e fertilizantes, aperfeiçoando, dessa maneira, o controle do sistema de produção das culturas, reduzindo possíveis impactos ao meio ambiente (SOUZA et al., 2004; SCHAFFRATH et al., 2008). Entretanto, torna-se necessário o uso de ferramentas de geoestatística que permitem observar a presença de dependência espacial, levando em consideração a distância na qual as amostras foram coletadas no campo.

A geoestatística vem sendo utilizada para caracterizar e quantificar a variabilidade espacial, desenvolver uma interpolação racional e estimar a variância dos valores interpolados (FENG et al., 2004). A caracterização da variabilidade espacial dos atributos do solo é essencial para alcançar a melhor compreensão das complexas relações entre as propriedades do solo e os fatores ambientais (GOOVERTS, 1998).

Diante dessa abordagem, o objetivo desse estudo foi avaliar a variabilidade espacial das propriedades químicas em Neossolo Quartzarênico Órtico típico em função da substituição do Cerrado por Pastagem de Brachiaria brizantha cv. Marandu, em área experimental, na cidade de Araguaína (TO).

\section{MATERIAL E MÉTODOS}

A área de estudo está situada entre as latitudes $7^{\circ} 5^{\prime} 37^{\prime \prime} \mathrm{S}$ e $7^{\circ} 5^{\prime} 33^{\prime}$ ' S e longitudes $48^{\circ} 12^{\prime} 16^{\prime \prime} \mathrm{W}$ e 48 11 ' $59^{\prime}$ " W, na fazenda da Escola de Medicina Veterinária e Zootecnia da Universidade Federal do Tocantins (EMVZ-UFT), Campus de Araguaína. De acordo com Köppen (1948), a região apresenta clima tipo Aw (quente úmido), com temperatura 
média de $28^{\circ} \mathrm{C}$ e precipitação pluviométrica média de $1800 \mathrm{~mm}$ anuais. O solo do local é classificado como Neossolo Quartzarênico Órtico típico (EMBRAPA, 2006).

As amostras do solo foram retiradas na profundidade de 0 a $20 \mathrm{~cm}$, com sonda de amostragem em 30 pontos georreferênciados em uma malha irregular de uma área total de 13,11 hectares, onde $54,39 \%$ do Cerrado nativo foi substituído e ocupado há três anos por pastagem de Brachiaria brizantha cv. Marandu. Assim sendo, em cada tipo de ocupação do solo, foram determinados 15 pontos de coleta (Figura 1). Na área ocupada pelo capim-Marandu, foi realizada a correção do solo com base na análise de solo, pelo método de saturação de bases trocáveis $\left(\mathrm{V}_{2}\right.$ $=50 \%$ ), com calcário dolomítico. $\mathrm{Na}$ adubação de fundação, foram aplicados $70 \mathrm{~kg} \mathrm{ha}^{-1}$ de fósforo $\left(\mathrm{P}_{2} \mathrm{O}_{5}\right)$ e potássio $\left(\mathrm{K}_{2} \mathrm{O}\right)$ e $50 \mathrm{~kg} \mathrm{ha}^{-1}$ de nitrogênio, tendo como fonte a ureia.

Após as coletas, todas as amostras de solo foram secadas ao ar e passadas em peneira de malha de 2,0 $0 \mathrm{~mm}$, tendo sido obtidas as amostras de terra fina seca ao ar (TFSA) para posteriores análises químicas no Laboratório de Solos da UFT. Nessas amostras de solo, foram determinados o valor de $\mathrm{pH}$ em $\mathrm{CaCl}_{2}$, os teores de $\mathrm{P}$ e $\mathrm{K}^{+}$extraíveis em Mehlich-1, os teores de cálcio $\left(\mathrm{Ca}^{2+}\right)$, magnésio $\left(\mathrm{Mg}^{2+}\right)$ e alumínio $\left(\mathrm{Al}^{3+}\right)$ trocáveis extraídos em $\mathrm{KCl} 1 \mathrm{~mol} \mathrm{~L}^{-1}$ e a matéria orgânica, de acordo com as recomendações da Embrapa (1999). Com os valores obtidos nas análises do solo, foram calculadas a capacidade de trocas de cátions (CTC) em pH 7,0, a CTC efetiva, a soma de bases trocáveis $(\mathrm{SB})$, a porcentagem de saturação por alumínio $(\mathrm{m} \%)$ e porcentagem de saturação por bases (V\%) (EMBRAPA, 1999).

Para cada atributo químico do solo estudado, foram feitas a análise estatística descritiva e a comparação de média pelo teste de Tukey, em nível de $5 \%$ probabilidade, com auxílio do software Assistat, versão 7,5 beta (SILVA, 2008). Na estatística descritiva, foram calculados a média, a mediana, a variância, a assimetria, a curtose, o coeficiente de variação e o tipo de distribuição. Utilizou-se o teste de Kolmogorov-Smirnov (KS), a $5 \%$ de probabilidade, para testar a hipótese de normalidade.

O padrão de dependência espacial foi caracterizado por meio de análise geoestatística (VIEIRA, 2000), tendo sido calculada a semivariância, utilizando o software $\mathrm{GS}^{+}$ (ROBERTSON, 2008), utilizando-se a Equação 1:

$$
\gamma(\mathrm{h})=\frac{1}{2 \mathrm{~N}(\mathrm{~h})} \sum_{\mathrm{i}=1}^{\mathrm{N}(\mathrm{h})}\left[\mathrm{Z}\left(\mathrm{x}_{\mathrm{i}}\right)-\mathrm{Z}\left(\mathrm{x}_{\mathrm{i}}+\mathrm{h}\right)\right]^{2}
$$

em que,

$\mathrm{N}(\mathrm{h})$ - o número de pares de valores experimentais medidos em $\left[\mathrm{Z}\left(\mathrm{x}_{\mathrm{i}}\right), \mathrm{Z}\left(\mathrm{x}_{\mathrm{i}}+\mathrm{h}\right)\right]$, separados pelo vetor $h$.

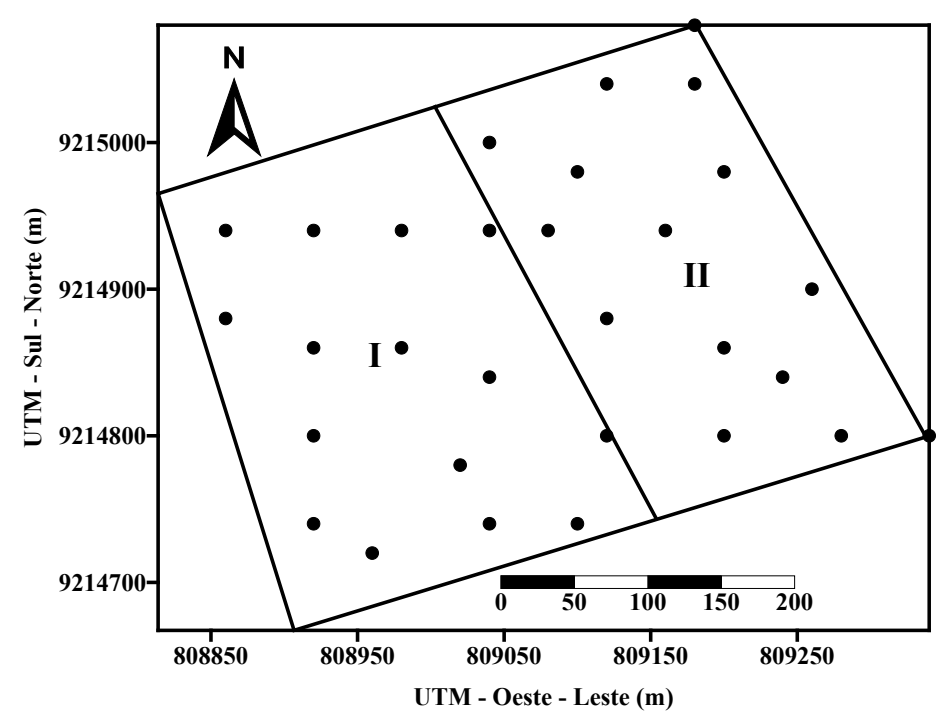

Figura 1. Local de coleta do solo nas classes de uso: Pastagem (I), Cerrado (II) 
No presente estudo, os valores de $\mathrm{Z}$ foram os atributos químicos do solo estudado, enquanto os valores de $\mathrm{x}_{\mathrm{i}}$ e $\mathrm{x}_{\mathrm{i}}+\mathrm{h}$ foram definidos de acordo com a localização geográfica das amostras feitas no campo.

Neste estudo, foram testados os modelos de semivariogramas: (a) esférico, $\gamma^{*}(\mathrm{~h})=\mathrm{C}_{0}+\mathrm{C}_{1}$ $\left[1,5(\mathrm{~h} / \mathrm{a})-0,5(\mathrm{~h} / \mathrm{a})^{3}\right]$ para $(0<\mathrm{h}<\mathrm{a})$ e $\gamma^{*}(\mathrm{~h})$ $=\mathrm{C}_{0}+\mathrm{C}_{1}$ para $\mathrm{h} \geq \mathrm{a}$; (b) exponencial, $\gamma^{*}(\mathrm{~h})=$ $\mathrm{C}_{0}+\mathrm{C}_{1}[1-\exp (-3 \mathrm{~h} / \mathrm{a})$ para $(0<\mathrm{h}<\mathrm{d})$; e (c) gaussiano, $\gamma^{*}(\mathrm{~h})=\mathrm{C}_{0}+\mathrm{C}_{1}\left[1-\exp \left(-3 \mathrm{~h}^{2} / \mathrm{a}^{2}\right)\right]$ para $(0<\mathrm{h}<\mathrm{d})$, em que $\mathrm{d}$ é a distância máxima na qual o semivariograma é definido. O ajuste dos semivariogramas possibilitou definir os valores do efeito pepita $\left(\mathrm{C}_{0}\right)$, do alcance $(\mathrm{A})$ e do patamar $\left(\mathrm{C}+\mathrm{C}_{0}\right)$.

A seleção do modelo ajustado dos semivariogramas foi feita com base na menor soma do quadrado dos resíduos (SQR), no maior coeficiente de determinação $\left(\mathrm{R}^{2}\right)$ e maior grau de dependência espacial (GDE). Segundo Robertson (2008), a proporção obtida utilizando-se a Equação 2:

$$
\mathrm{GDE}=\left[\frac{\mathrm{C}}{\mathrm{C}+\mathrm{C}_{0}}\right] \times 100
$$

Utilizando-se a Equação 2, pode ser feita a classificação do GDE em: dependência espacial fraca em GDE $\leq 25 \%$, dependência espacial moderada quando $25 \%<\mathrm{GDE} \leq 75 \%$ e dependência espacial forte em GDE $>75 \%$. No presente estudo, também foi feita a validação cruzada para analisar a qualidade do modelo matemático ajustado dos semivariogramas para cada uma das propriedades do solo estudado.

A interpolação dos valores foi feita pelo método geoestatístico de Krigagem Ordinária, de modo a definir o padrão espacial das variáveis estudadas, o que permitiu a elaboração dos mapas de isolinhas, utilizando-se o software Surfer 8.0 (GOLDEN SOFTWARE, 2002), com o auxílio da Equação 3:

$$
\mathrm{Z} *\left(\mathrm{x}_{0}\right)=\sum_{\mathrm{i}=1}^{\mathrm{N}} \lambda_{\mathrm{i}} \mathrm{Z}\left(\mathrm{x}_{\mathrm{i}}\right)
$$

em que,

$\mathrm{Z}^{*}\left(\mathrm{x}_{0}\right)=$ variável interpolada;

$\lambda_{i}=$ peso da i-ésima localidade vizinha;

$\mathrm{Z}\left(\mathrm{x}_{\mathrm{i}}\right)=$ valor da variável para a i-ésima localidade; e

$\mathrm{N}$ = número de localidades vizinhas empregadas para interpolação do ponto (VIEIRA, 2000).

\section{RESULTADOS E DISCUSSÃO}

A comparação de médias dos atributos químicos do solo é apresentada no Quadro 1. Entre os parâmetros da fertilidade estudados, o local ocupado pela vegetação de Cerrado apresentou valores altos de $\mathrm{pH}$ e de $\mathrm{m} \%$ e baixos de soma de bases, $\mathrm{CTC}_{\mathrm{pH}}$ e CTC em comparação com a pastagem de Brachiaria brizantha cv. Marandu. Situação esperada, pois, segundo Sousa \& Lobato (2004), os solos de Cerrado apresentam naturalmente baixos valores de $\mathrm{pH}$, elevados teores de alumínio trocável e baixos teores de $\mathrm{Ca}^{2+}$ e $\mathrm{Mg}^{2+}$, ou seja, com características restritivas ao desenvolvimento vegetal. Tais resultados têm um reflexo direto no manejo, tornando necessária a recuperação química dessa região de Cerrado.

A substituição do Cerrado pela pastagem, aliada à correção e adubação química, elevou os teores de $\mathrm{P}, \mathrm{Ca}^{2+}, \mathrm{Mg}^{2+}$ e reduziu o teor de $\mathrm{Al}^{3+}$ e o valor de $\mathrm{pH}$, o que concorda com resultados de Carneiro et al. (2009). Segundo Macedo (1995), as pastagens de braquiárias no Cerrado sofrem declínio na produtividade após 4 a 10 anos de pastejo, devido à ausência de adubação de manutenção, o que é comum em grandes áreas do Brasil. Situação encontrada por Santos et al. (2009), Fraga \& Salcedo (2004) e Tiessen et al. (1992), que observaram que o avanço da agropecuária sobre matas nativas levou ao empobrecimento geral do solo ao longo do tempo.

Apesar de as áreas de pastagem apresentarem valores mais altos nas propriedades químicas do solo (pH, P, $\mathrm{Ca}^{+2}, \mathrm{Mg}^{+2}, \mathrm{SB}, \mathrm{CTC}_{\mathrm{pH} 7}, \mathrm{CTC}_{\mathrm{e}}, \mathrm{V} \%$ ) em relação ao Cerrado, essas propriedades podem não garantir a sustentabilidade do sistema de produção, pois, de acordo com a CFSMG (1999), os valores médios dos atributos químicos do solo na camada de 0-20 $\mathrm{cm}$ apresentam classe de fertilidade média para $\mathrm{Mg}^{2+}$, baixa para $\mathrm{Ca}^{2+}, \mathrm{SB}$ e $\mathrm{CTC}_{\mathrm{e}}$ e muito baixa para $\mathrm{P}$ e $\mathrm{V}(\%)$, ou seja, baixo 
potencial agrícola. Entretanto, valores elevados de $\mathrm{pH}$ e muito baixos de $\mathrm{m}(\%)$ indicam que uma menor proporção do complexo de troca do solo na área de pastagem está sendo ocupada pelos íons $\mathrm{H}^{+}$ e $\mathrm{Al}^{3+}$.

As alterações na fertilidade do solo observadas em função da ocupação do Cerrado pela pastagem indicam que o detalhamento desse universo é uma necessidade comprovada pela sua evidente variabilidade química. Assim sendo, tornou-se necessária a identificação da distribuição espacial das variáveis químicas do solo por meio de estudo de geoestatística para definição das zonas de manejo do solo e avaliação dos efeitos da agropecuária sobre a qualidade ambiental, em função da ocupação do solo.

Os resultados referentes à análise descritiva para os parâmetros da fertilidade do solo são apresentados no Quadro 2. O teste de normalidade de Kolmogorov Smirnov indicou normalidade apenas para as variáveis $\mathrm{MO}, \mathrm{Mg}, \mathrm{CTC}_{\mathrm{pH} 7}$ e $\mathrm{CTC}_{\mathrm{e}}$ e o mesmo não foi observado para os demais parâmetros químicos. Segundo Corá et al. (2006), o estudo geoestatístico de um conjunto de dados não exige que eles tenham distribuição normal. Estudando atributos químicos do solo, Corá et al. (2004) obtiveram resultados bem parecidos com os deste estudo, visto que somente a $\mathrm{CTC}_{\mathrm{pH} 7}$ e os teores de $\mathrm{K}^{+}$apresentavam distribuição normal. Carvalho et al. (2003), estudando a variabilidade dos atributos químicos do solo, encontraram distribuição normal para $\mathrm{pH}, \mathrm{V} \%$, e o $\mathrm{Ca}$ e $\mathrm{Mg}$ mostraram distribuição lognormal.

Os coeficientes de assimetria e curtose mostram que os atributos químicos do solo têm distribuições assimétricas. Apesar disto, os valores da média e mediana de todos os atributos químicos estudados estão bem próximos, indicando que o conjunto de dados não apresenta assimetria acentuada, pois, segundo Little \& Hills (1978), quando os valores da média e mediana são semelhantes, os dados apresentam ou se aproximam da distribuição normal.

Os valores do coeficiente de variação $(\mathrm{CV})$ indicam que o conjunto de dados apresenta alto grau de heterogeneidade, o que não foi observado para os valores de $\mathrm{pH}$, que foram baixos $(8,43 \%)$, segundo Gomes (1984). Pesquisas de Carvalho et al. (2002), Silva et al. (2003) e Souza et al. (2004) confirmam os resultados alcançados nesse estudo. Segundo Corá et al. (2004), isso acontece por causa da concentração de nutrientes em alguns locais e não em outros, situação ocorrida nessa investigação porquanto a fertilização química da pastagem contribuiu para elevar os teores de nutrientes em relação ao Cerrado, aumentando o CV e a heterogeneidade.

Quadro 1. Características químicas nas classes de uso do Neossolo Quartzarênico Órtico típico

\begin{tabular}{|c|c|c|c|}
\hline \multirow{2}{*}{ Variável } & \multicolumn{2}{|c|}{ Local } & \multirow{2}{*}{$\operatorname{CV}(\%)$} \\
\hline & Cerrado & Pastagem & \\
\hline $\mathrm{MO}\left(\mathrm{g} \mathrm{dm}^{-3}\right)$ & $11,44^{\mathrm{ns}}$ & $9,86^{\mathrm{ns}}$ & 30,69 \\
\hline $\mathrm{pH}\left(\mathrm{CaCl}_{2}\right)$ & $4,83 \mathrm{~b}$ & $5,50 \mathrm{a}$ & 5,31 \\
\hline $\mathrm{Al}^{3+}\left(\mathrm{cmol}_{\mathrm{c}} \mathrm{dm}^{-3}\right)$ & $0,96 \mathrm{a}$ & $0,25 \mathrm{~b}$ & 51,71 \\
\hline $\mathrm{P}\left(\mathrm{mg} \mathrm{dm}^{-3}\right)$ & $0,57 \mathrm{~b}$ & $0,72 \mathrm{a}$ & 17,37 \\
\hline $\mathrm{K}^{+}\left(\mathrm{mg} \mathrm{dm}^{-3}\right)$ & $1,08^{\mathrm{ns}}$ & 0,93 ns & 41,11 \\
\hline $\mathrm{Ca}^{2+}\left(\mathrm{cmol}_{\mathrm{c}} \mathrm{dm}^{-3}\right)$ & $0,21 \mathrm{~b}$ & $0,86 \mathrm{a}$ & 66,20 \\
\hline $\mathrm{Mg}^{2+}\left(\mathrm{cmol}_{\mathrm{c}} \mathrm{dm}^{-3}\right)$ & $0,36 \mathrm{~b}$ & $0,68 \mathrm{a}$ & 41,91 \\
\hline $\mathrm{SB}\left(\mathrm{cmol}_{\mathrm{c}} \mathrm{dm}^{-3}\right)$ & $0,47 \mathrm{~b}$ & $1,67 \mathrm{a}$ & 35,26 \\
\hline $\mathrm{CTC}_{\mathrm{pH} 7}\left(\mathrm{cmol}_{\mathrm{c}} \mathrm{dm}^{-3}\right)$ & $6,43 \mathrm{~b}$ & $8,75 \mathrm{a}$ & 21,36 \\
\hline $\mathrm{CTC}_{\mathrm{e}}\left(\mathrm{cmol}_{\mathrm{c}} \mathrm{dm}^{-3}\right)$ & $1,43 \mathrm{~b}$ & $1,93 \mathrm{a}$ & 24,73 \\
\hline $\mathrm{V}(\%)$ & $7,96 \mathrm{~b}$ & $19,47 \mathrm{a}$ & 36,96 \\
\hline $\mathrm{m}(\%)$ & $65,71 \mathrm{a}$ & $13,64 \mathrm{~b}$ & 33,24 \\
\hline
\end{tabular}

Médias seguidas de mesma letra na linha não diferem entre si ao nível de probabilidade de 5\% pelo teste de Tukey, MO: matéria orgânica; $\mathrm{SB}$ : soma de base; $\mathrm{CTC}_{\mathrm{pH}}$ : capacidade de troca de cátions a pH7; $\mathrm{CTC}_{\mathrm{e}}$ : capacidade de troca de cátions efetiva; V: saturação por base; m: saturação por alumínio; CV: coeficiente de variação 
Quadro 2. Estatística descritiva dos atributos da fertilidade do Neossolo Quartzarênico Órtico típico

\begin{tabular}{|c|c|c|c|c|c|c|c|}
\hline \multirow{2}{*}{ Variável } & \multirow{2}{*}{ Média } & \multirow{2}{*}{ Mediana } & \multirow{2}{*}{ Variância } & \multicolumn{3}{|c|}{ Coeficiente } & \multirow{2}{*}{$\mathbf{K S}^{1}$} \\
\hline & & & & Variação & Assimetria & Curtose & \\
\hline $\mathrm{MO}\left(\mathrm{g} \mathrm{dm}^{-3}\right)$ & 10,66 & 10,63 & 10,98 & 31,09 & 0,09 & 0,24 & $0,10^{*}$ \\
\hline $\mathrm{pH}\left(\mathrm{CaCl}_{2}\right)$ & 5,17 & 4,96 & 0,19 & 8,43 & 0,66 & $-0,84$ & $0,22^{* *}$ \\
\hline $\mathrm{Al}^{3+}\left(\mathrm{cmol}_{\mathrm{c}} \mathrm{dm}^{-3}\right)$ & 0,61 & 0,53 & 0,22 & 77,75 & 0,42 & $-1,02$ & $0,17^{*}$ \\
\hline $\mathrm{P}\left(\mathrm{mg} \mathrm{dm}^{-3}\right)$ & 0,65 & 0,59 & 0,02 & 20,81 & 0,57 & $-1,07$ & $0,19^{* *}$ \\
\hline $\mathrm{K}^{+}\left(\mathrm{mg} \mathrm{dm}^{-3}\right)$ & 1,00 & 0,77 & 0,17 & 41,15 & 0,17 & $-0,53$ & $0,38^{* *}$ \\
\hline $\mathrm{Ca}^{2+}\left(\mathrm{cmol}_{\mathrm{c}} \mathrm{dm}^{-3}\right)$ & 0,53 & 0,36 & 0,23 & 89,97 & 0,75 & $-0,32$ & $0,25^{* *}$ \\
\hline $\mathrm{Mg}^{2+}\left(\mathrm{cmol}_{\mathrm{c}} \mathrm{dm}^{-3}\right)$ & 0,52 & 0,45 & 0,07 & 51,63 & 0,63 & $-0,76$ & $0,13^{*}$ \\
\hline $\mathrm{SB}\left(\mathrm{cmol}_{\mathrm{c}} \mathrm{dm}^{-3}\right)$ & 1,07 & 0,83 & 0,51 & 66,63 & 0,72 & $-0,48$ & $0,19^{* *}$ \\
\hline $\mathrm{CTC}_{\mathrm{pH} 7}\left(\mathrm{cmol}_{\mathrm{c}} \mathrm{dm}^{-3}\right)$ & 7,59 & 7,12 & 3,92 & 26,10 & 0,43 & $-0,31$ & $0,14^{*}$ \\
\hline $\mathrm{CTC}_{\mathrm{e}}\left(\mathrm{cmol}_{\mathrm{c}} \mathrm{dm}^{-3}\right)$ & 1,68 & 1,56 & 0,23 & 28,60 & 0,66 & 0,07 & $0,13^{*}$ \\
\hline$V(\%)$ & 13,71 & 13,33 & 59,03 & 56,02 & 0,50 & $-0,83$ & $0,19^{* *}$ \\
\hline m (\%) & 39,67 & 42,42 & 869,13 & 74,30 & $-0,05$ & $-1,84$ & $0,20^{* *}$ \\
\hline
\end{tabular}

${ }^{(1)} \mathrm{KS}$ : teste de normalidade de Kolmogorov Smirnov, ${ }^{(*)}$ : $\operatorname{significativo~a~} 5 \%,{ }^{(* *)}$ : não-significativo a $5 \%$, M,O: matéria orgânica; $\mathrm{SB}$ : soma de base; $\mathrm{CTC}_{\mathrm{pH} 7}$ : capacidade de troca de cátions a $\mathrm{pH} 7 \mathrm{CTC}_{\mathrm{e}}$ : capacidade de troca de cátions efetiva; V: saturação por base; m: saturação por alumínio

Quadro 3. Modelos e parâmetros estimados dos semivariogramas experimentais e os resultados da validação cruzada das propriedades do Neossolo Quartzarênico Órtico típico

\begin{tabular}{|c|c|c|c|c|c|c|c|c|c|c|}
\hline \multirow{2}{*}{ Atributo } & \multicolumn{8}{|c|}{ Parâmetro } & \multicolumn{2}{|c|}{$\begin{array}{c}\text { Validação } \\
\text { cruzada }\end{array}$} \\
\hline & Modelo & $\mathrm{C}_{0}{ }^{1}$ & $\mathrm{C}_{0}+\mathrm{C}^{2}$ & $\mathbf{A}^{3}(\mathbf{m})$ & $\operatorname{GDE}^{4}(\%)$ & Classe & $\mathbf{R}^{2^{*}}$ & $\mathrm{SQR}^{5}$ & $\mathbf{R}^{2^{*}}$ & $\mathrm{CR}^{6}$ \\
\hline MO & Esférico & 8,53 & 17,07 & 910,90 & 50 & Moderada & 0,20 & 52,20 & 0,10 & 0,56 \\
\hline $\mathrm{pH}$ & Esférico & 0,015 & 0,23 & 266,80 & 93 & Forte & 0,84 & $4,44^{-3}$ & 0,55 & 1,00 \\
\hline $\mathrm{Al}^{3+}$ & Esférico & 0,078 & 0,54 & 910,90 & 85 & Forte & 0,83 & 0,011 & 0,36 & 0,90 \\
\hline $\mathrm{P}$ & Esférico & 0,008 & 0,036 & 810,40 & 78 & Forte & 0,84 & $4,19^{-5}$ & 0,16 & 0,73 \\
\hline $\mathrm{K}^{+}$ & Esférico & 0,090 & 0,360 & 910,90 & 75 & Moderada & 0,56 & 0,013 & 0,10 & 0,15 \\
\hline $\mathrm{Ca}^{2+}$ & Esférico & 0,062 & 0,260 & 242,20 & 76 & Forte & 0,69 & $7,58^{-3}$ & 0,52 & 1,00 \\
\hline $\mathrm{Mg}^{2+}$ & Exponencial & 0,043 & 0,120 & 802,90 & 64 & Moderada & 0,50 & $1,61^{-3}$ & 0,27 & 0,99 \\
\hline $\mathrm{SB}$ & Exponencial & 0,150 & 1,141 & 830,40 & 87 & Forte & 0,85 & 0,045 & 0,52 & 1,00 \\
\hline $\mathrm{CTC}_{\mathrm{pH} 7}$ & Esférico & 2,02 & 5,433 & 484,40 & 63 & Moderada & 0,85 & 1,180 & 0,13 & 0,64 \\
\hline $\mathrm{CTC}_{\mathrm{e}}$ & Esférico & 0,170 & 0,341 & 910,90 & 50 & Moderada & 0,10 & 0,015 & 0,10 & 0,78 \\
\hline $\mathrm{V} \%$ & Esférico & 17,10 & 145,10 & 910,90 & 88 & Forte & 0,78 & 1041 & 0,30 & 0,82 \\
\hline $\mathrm{m} \%$ & Esférico & 1,00 & 2112 & 685,70 & 100 & Forte & 0,91 & 219034 & 0,66 & 0,93 \\
\hline
\end{tabular}

${ }^{\left({ }^{(1)}\right.} \mathrm{C}_{0}$ : efeito pepita; ${ }^{(2)} \mathrm{C}_{0}+\mathrm{C}$ : patamar; ${ }^{(3)} \mathrm{A}$ : alcance; ${ }^{(4)} \mathrm{GDE}$ : grau de dependência espacial; ${ }^{(5)} \mathrm{SQR}$ : Soma do quadrado dos resíduos, ${ }^{(6)} \mathrm{CR}$ : coeficiente de regressão, ${ }^{\left({ }^{*}\right.} \mathrm{R}^{2}$ : coeficiente de determinação

Para cada parâmetro da fertilidade do solo analisado, ajustaram-se os modelos dos semivariogramas considerando os valores do coeficiente de determinação $\left(\mathrm{R}^{2}\right)$ e soma do quadrado dos resíduos (SQR) (Quadro 3). Segundo Robertson (2008), a SQR é um parâmetro mais robusto do que o $\mathrm{R}^{2}$, propiciando uma medida exata à qual o modelo se ajusta melhor aos dados. $\mathrm{O}$ programa $\mathrm{GS}^{+}$utiliza a combinação de parâmetros do semivariograma para minimizar a $\mathrm{SQR}$ para cada modelo.

Todas as características da fertilidade do solo 
analisados apresentaram dependência espacial na profundidade estudada. Os atributos $\mathrm{MO}, \mathrm{pH}$, $\mathrm{Al}^{+}, \mathrm{P}, \mathrm{K}^{+}, \mathrm{Ca}^{2+}, \mathrm{CTC}_{\mathrm{pH}}, \mathrm{CTC}_{\mathrm{e}}, \mathrm{V} \%$ e $\mathrm{m} \%$ do solo se ajustaram ao modelo esférico e apenas o $\mathrm{Mg}^{2+}$ e a SB, ao modelo exponencial (Quadro 3). Resultados que concordam com os observados por várias pesquisas que mostram que o modelo esférico ocorre com maior frequência em relação aos outros modelos (SOUZA et al. 1997; SOUZA et al. 2004; GREGO \& VIEIRA, 2005; GOMES et al., 2008). No entanto, Corá et al. (2004) e Corrêa et al. (2009) encontraram resultado contrário, tendo em vista que na maioria das vezes o ajuste do modelo foi do tipo exponencial.

$\mathrm{O}$ coeficiente de determinação $\left(\mathrm{R}^{2}\right)$ dos modelos ajustados para $\mathrm{MO}$ e $\mathrm{CTC}_{\mathrm{e}}$ apresentaram os menores valores, 0,20 e 0,10 , respectivamente. $\mathrm{O} \mathrm{R}^{2}$ dos modelos ajustados para os teores de $\mathrm{K}^{+}$, $\mathrm{Ca}^{2+} \mathrm{e} \mathrm{Mg}^{2+}$ apresentou valores intermediários, respectivamente, 0,$56 ; 0,69$ e 0,50 . Já as demais características da fertilidade do solo apresentaram valores de $R^{2}$ superiores, variando entre 0,78 e 0,91 .

A análise do grau de dependência espacial (GDE) permitiu classificar as variáveis $\mathrm{pH}$, $\mathrm{Al}^{3+}, \mathrm{P} \mathrm{Ca}^{2+}, \mathrm{SB}, \mathrm{V} \%$ e $\mathrm{m} \%$ como fortemente dependentes espacialmente, e as outras, MO, $\mathrm{K}^{+}, \mathrm{Mg}^{3+}, \mathrm{CTC}_{\mathrm{pH} 7}, \mathrm{CTC}_{\mathrm{e}}$, como sendo de GDE moderado. De acordo com Cambardella et al. (1994) e Castrignanò et al. (2000), a forte dependência espacial das características químicas do solo é atribuída a fatores intrínsecos tais como a mineralogia, a textura e a dependência espacial moderada dos fatores extrínsecos como o manejo do solo adotado. Situação semelhante foi observada por Cavalcante et al. (2007), estudando diferentes sistemas de uso e manejo do solo.

$\mathrm{O}$ alcance (A) de um atributo garante que todos os pontos dentro de um círculo com este raio são tão similares que podem ser usados para estimar valores para qualquer ponto entre eles (MACHADO et al., 2007). A maioria das características químicas do solo apresentou diferentes alcances, no entanto, os teores de M.O, $\mathrm{Al}^{3+}, \mathrm{K}^{+}, \mathrm{CTC}_{\mathrm{e}}$ e $\mathrm{V} \%$ se mantiveram iguais e apresentaram os maiores valores de alcances, isso é $910,90 \mathrm{~m}$. Já o valor de $\mathrm{pH}$ e o teor de $\mathrm{Ca}^{2+}$ tiveram os menores alcances, 266,80 e 242,20 m, respectivamente. A menor continuidade espacial do $\mathrm{pH}$ e $\mathrm{Ca}^{2+}$ pode ser explicada pelas práticas de adubos e correção do solo de forma descontínua, pois as áreas de Cerrado não receberam nenhum tipo de fertilização e correção.

Segundo Grego \& Vieira (2005), os valores do alcance relativos aos semivariogramas têm uma importância considerável na determinação do limite da dependência espacial, podendo ser também um indicativo do intervalo entre unidades de mapeamento de solos. Assim, os valores altos de alcance dos atributos $\mathrm{MO}, \mathrm{Al}^{3+}, \mathrm{K}^{+}, \mathrm{P}$, $\mathrm{Mg}^{2+}$, SB CTC e $\mathrm{e} \%$, que variaram de 802,90 a $910,90 \mathrm{~m}$, indicam que, apesar dos manejos do solo realizados ao longo do tempo, tais como aplicações de fertilizantes e calcário e preparo convencional do solo com arações e gradagens na área de pastagem, não foram capazes de interferir de modo a diminuir a continuidade na distribuição espacial dessas variáveis.

A partir dos modelos obtidos, Figuras 2 e 3 , para os semivariogramas ajustados para cada variável do estudo, estimaram-se os valores das variáveis químicas para locais não amostrados através do método de interpolação de Krigagem Ordinária. Assim, com os valores estimados, foi possível construir mapas de isolinhas que expressam a variabilidade das características químicas avaliadas. Para Isaaks \& Srivastava (1989), a magnitude do efeito pepita $\left(\mathrm{C}_{0}\right)$ é importante na Krigagem, pois quanto maior for a diferença do $\mathrm{C}_{0}$ em relação ao patamar $\left(\mathrm{C}_{0}+\mathrm{C}\right)$ do semivariograma, maior a continuidade do fenômeno, menor a variância da estimativa e maior será a confiança que se pode ter na predição.

A partir dos mapas gerados, Figuras 4 e 5, pode-se observar um arranjo de distribuição espacial dos atributos químicos bem definidos entre as duas áreas estudadas, o que permitiu identificar zonas homogêneas de fertilidade do solo sob pastagem e Cerrado bem distintas para a maioria das variáveis estudadas. Desse modo, observa-se que o avanço da pastagem sobre área de Cerrado traz alteração nos parâmetros da fertilidade do solo. Essa identificação das áreas quanto à sua qualidade facilita o monitoramento da fertilidade do solo e da qualidade ambiental. 
A.
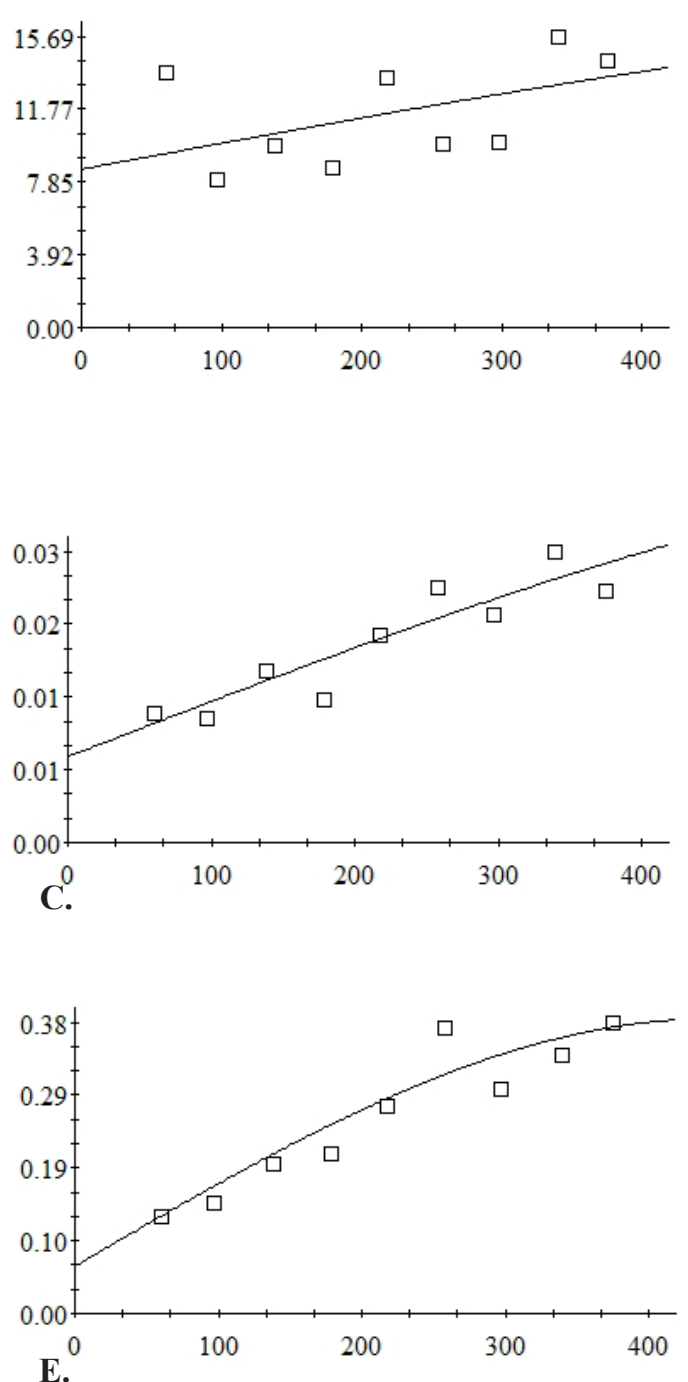

B. C.

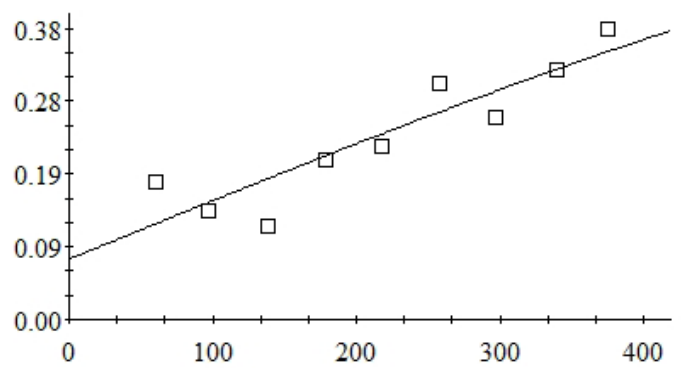

D.

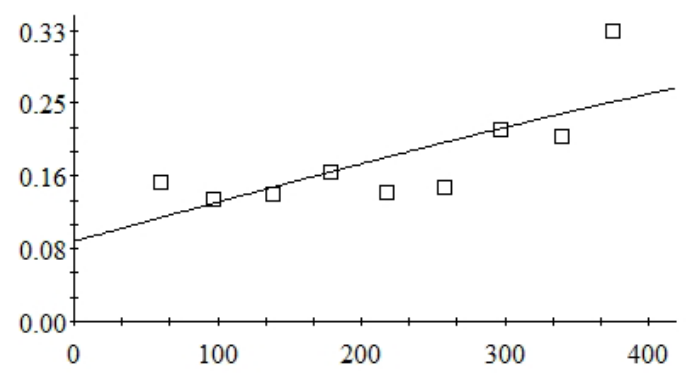

F.

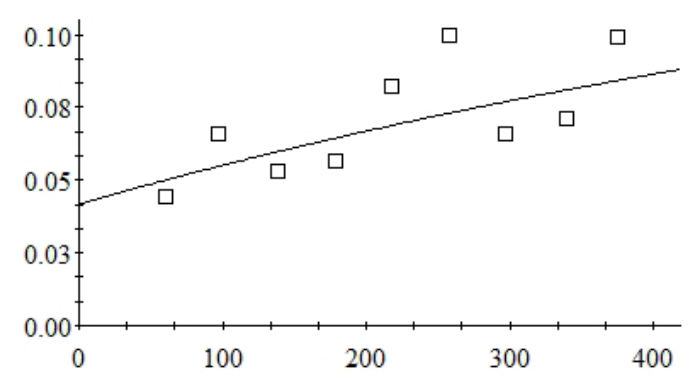

\section{Distância (m)}

Figura 2. Semivariogramas isotrópicos experimentais e teóricos das propriedades químicas do solo, (A.) $\mathrm{MO}\left(\mathrm{g} \mathrm{dm}^{-3}\right)$, (B.) $\mathrm{Al}^{3+}\left(\mathrm{cmol}_{\mathrm{c}} \mathrm{dm}^{-3}\right)$, (C.) P $\left(\mathrm{mg} \mathrm{dm}^{-3}\right)$, (D.) $\mathrm{K}^{+}\left(\mathrm{mg} \mathrm{dm} \mathrm{dm}^{-3}\right)$, (E.) $\mathrm{Ca}^{2+}\left(\mathrm{cmol}_{\mathrm{c}} \mathrm{dm}^{-3}\right)$ e (F.) $\mathrm{Mg}^{2+}\left(\mathrm{cmol}_{\mathrm{c}} \mathrm{dm}^{-3}\right)$ em função das classes de uso do solo, (I) Pastagem, (II) Cerrado 
A.
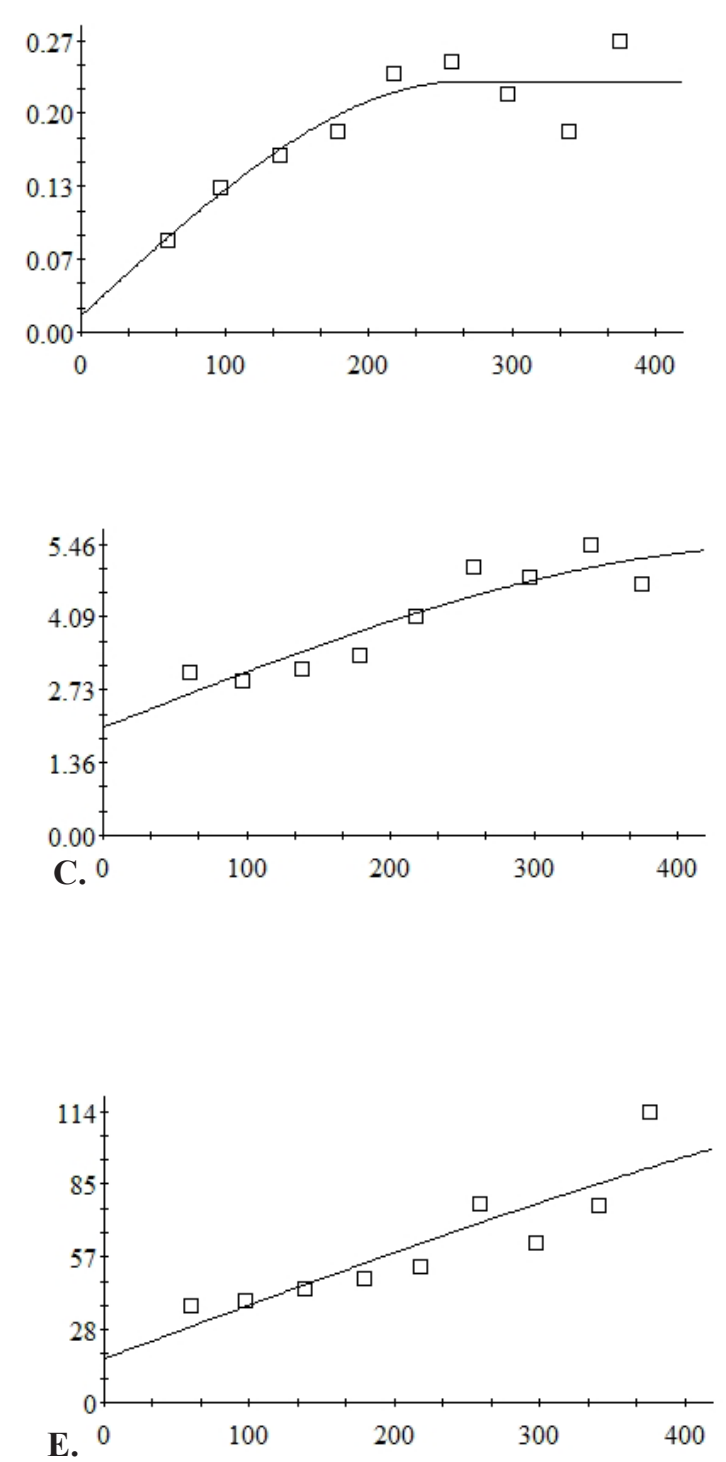

B.

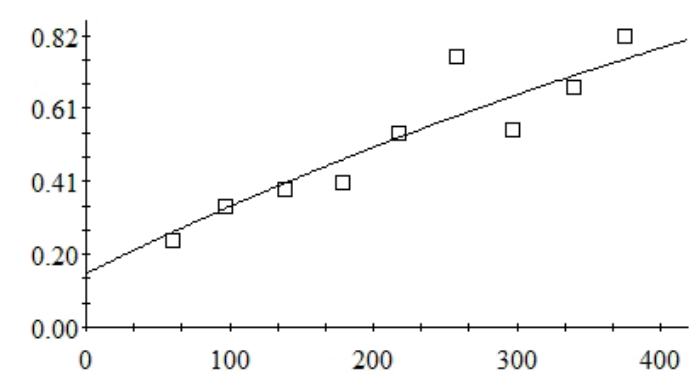

D.

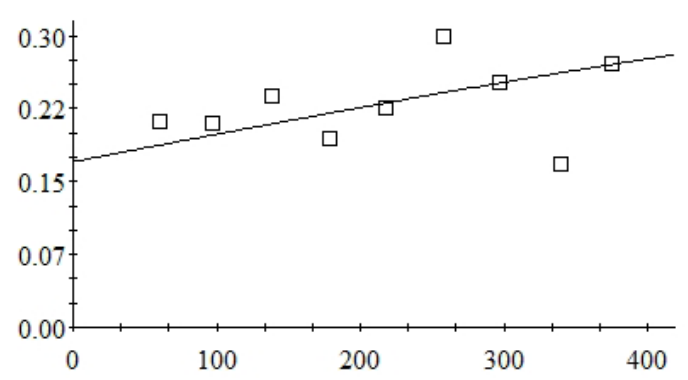

F.

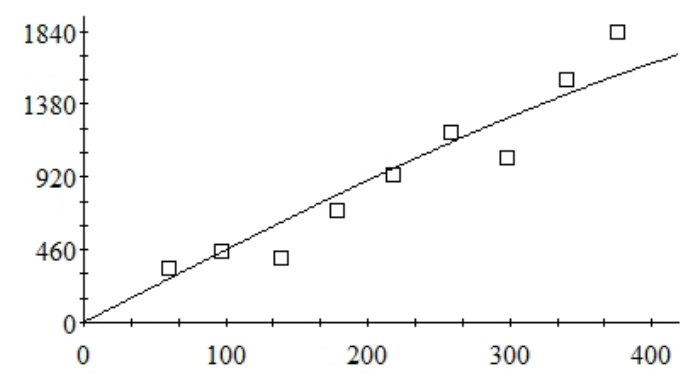

\section{Distância (m)}

Figura 3. Semivariogramas isotrópicos experimentais e teóricos das propriedades químicas do solo, (A.) $\mathrm{pH}\left(\mathrm{CaCl}_{2}\right)$, (B.) Soma de bases $\left(\mathrm{cmol}_{\mathrm{c}} \mathrm{dm}^{-3}\right)$, (C.) $\mathrm{CTC}_{\mathrm{pH} 7}\left(\mathrm{cmol}_{\mathrm{c}} \mathrm{dm}^{-3}\right)$, (D.) $\mathrm{CTC}_{\mathrm{e}}\left(\mathrm{cmol}_{\mathrm{c}} \mathrm{dm}^{-3}\right)$, (E.) $\mathrm{V} \%$, (F.) $\mathrm{m} \%$, em função das classes de uso do solo, (I) Pastagem, (II) Cerrado 
A.

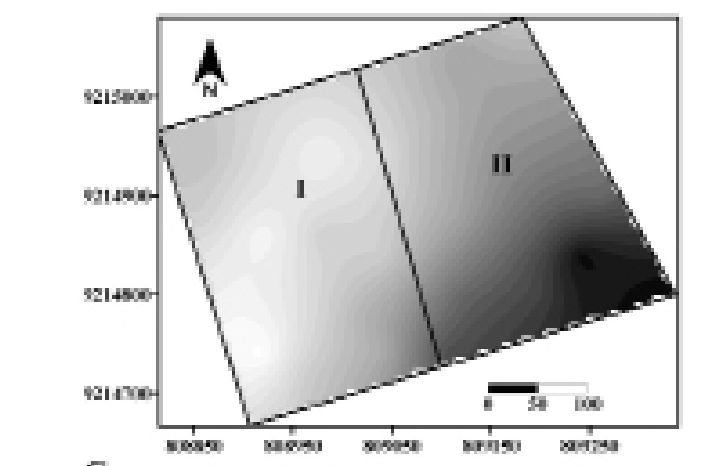

C.

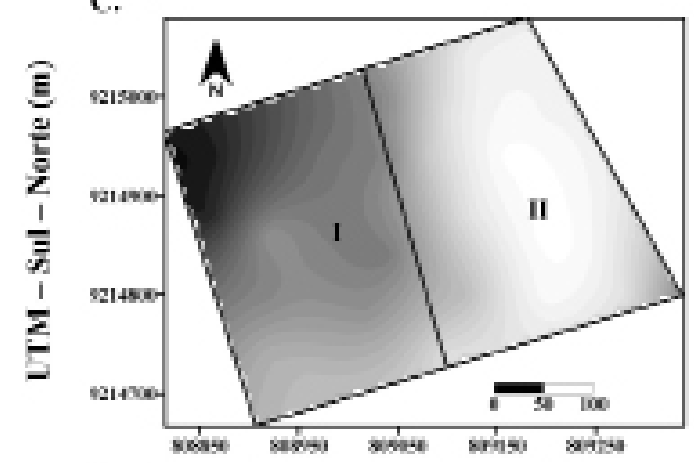

E.

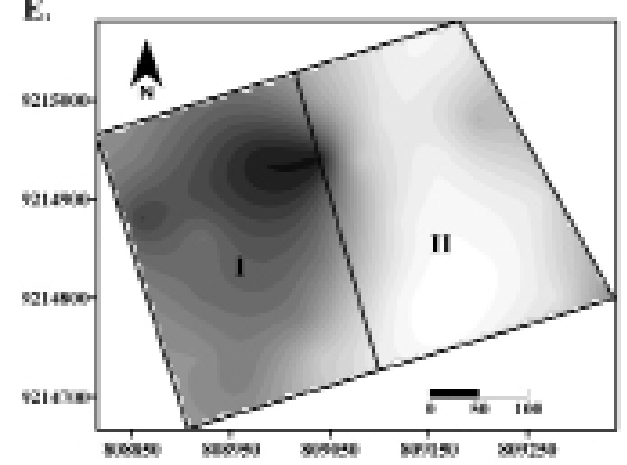

B.
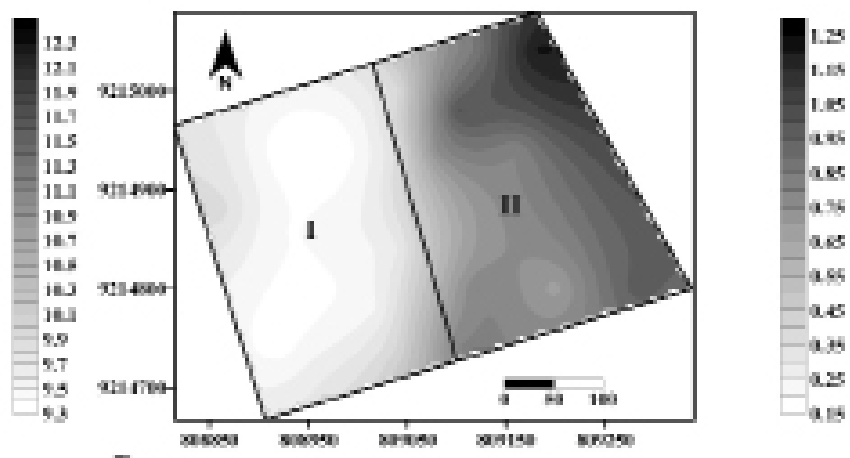

D.
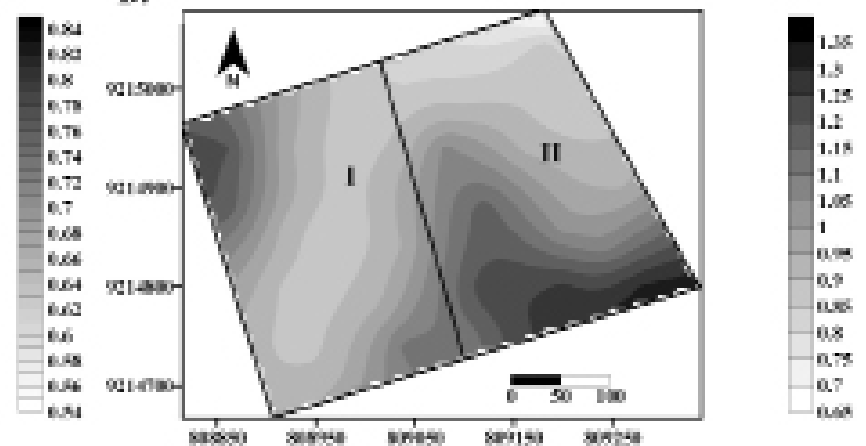

F.

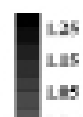

1.25
L.1.5
L.5

A
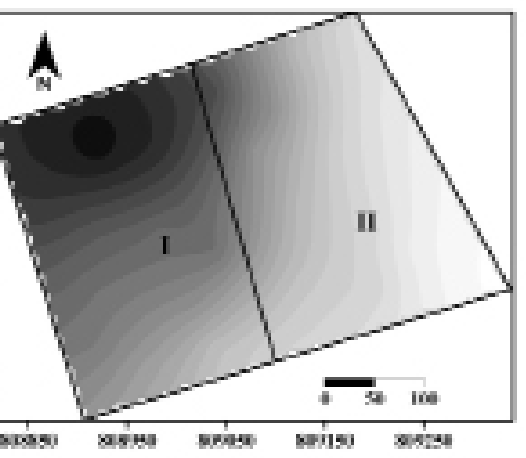

UTM - Ovste - Leste (m)

Figura 4. Mapas de isolinhas da distribuição espacial dos atributos químicos do solo, (A.) $\mathrm{MO}\left(\mathrm{g} \mathrm{dm}^{-3}\right)$, (B.) $\mathrm{Al}^{3+}\left(\mathrm{cmol}_{\mathrm{c}} \mathrm{dm}^{-3}\right)$, (C.) $\mathrm{P}(\mathrm{mg} \mathrm{dm}-3)$, (D.) $\mathrm{K}^{+}\left(\mathrm{mg} \mathrm{dm}^{-3}\right)$, (E.) $\mathrm{Ca}^{2+}\left(\mathrm{cmol}_{\mathrm{c}} \mathrm{dm}^{-3}\right)$ e (F.) $\mathrm{Mg}^{2+}$ $\left(\mathrm{cmol}_{\mathrm{c}} \mathrm{dm}^{-3}\right)$ em função das classes de uso do solo, (I) Pastagem, (II) Cerrado 

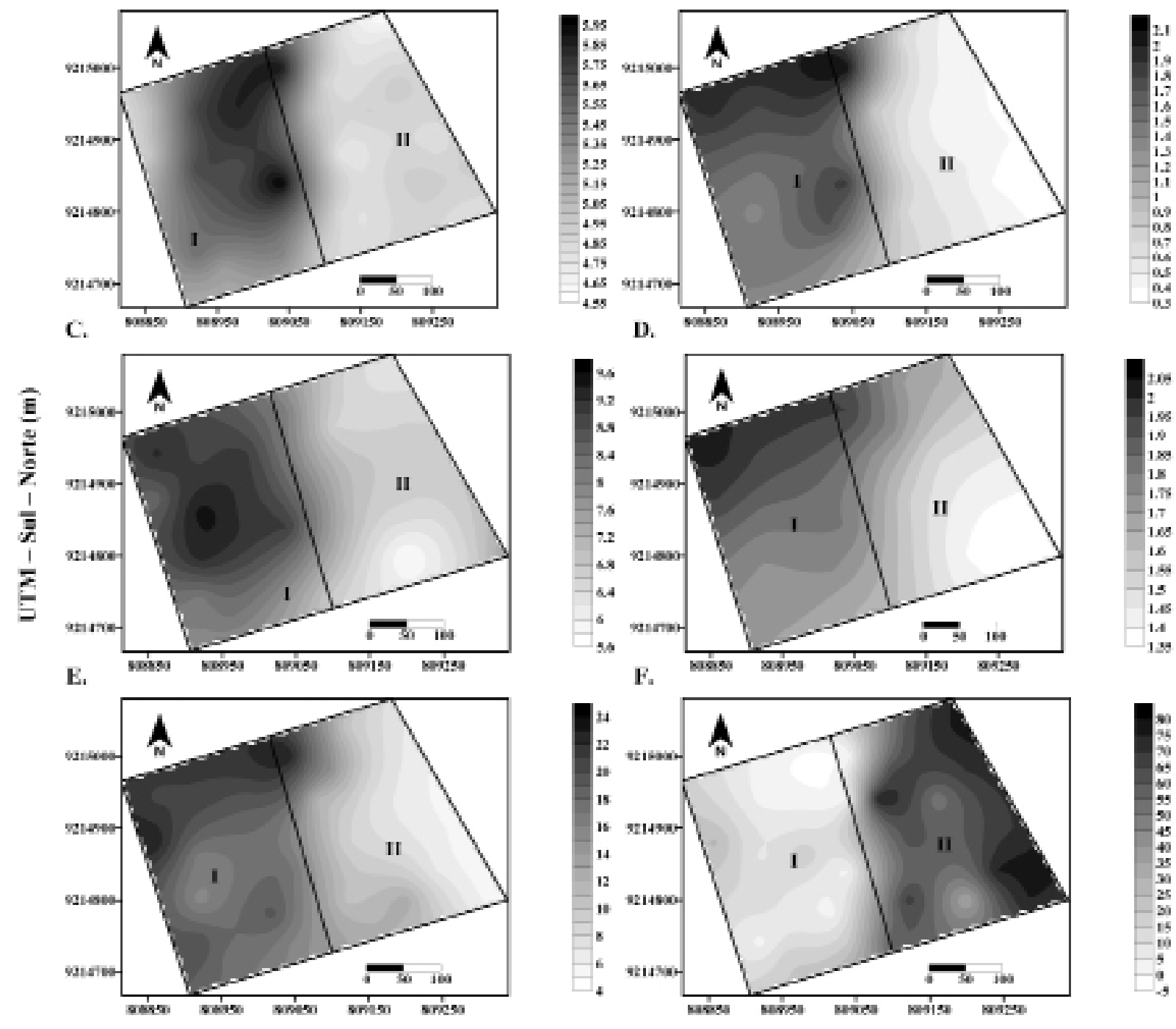

\section{UTM - Oeste - Leste (m)}

Figura 5. Mapas de isolinhas da distribuição espacial dos valores de, (A.) $\mathrm{pH}\left(\mathrm{CaCl}_{2}\right)$, (B.) Soma de bases $\left(\mathrm{cmol}_{\mathrm{c}} \mathrm{dm}^{-3}\right)$, (C.) $\mathrm{CTC}_{\mathrm{pH} 7}\left(\mathrm{cmol}_{\mathrm{c}} \mathrm{dm}^{-3}\right)$, (D.) $\mathrm{CTC}_{\mathrm{e}}\left(\mathrm{cmol}_{\mathrm{c}} \mathrm{dm}^{-3}\right)$, (E.) $\mathrm{V} \%$, (F.) $\mathrm{m} \%$, em função das classes de uso do solo, (I) Pastagem, (II) Cerrado 


\section{CONCLUSÕES}

- A substituição do Cerrado nativo por pastagem trouxe melhorias nas características químicas do solo, no entanto, o solo sob pastagem apresenta baixa fertilidade em função do manejo de adubação e de correção adotado;

- O menor alcance de dependência espacial foi encontrado nos valores de $\mathrm{pH}$ e no teor de $\mathrm{Ca}^{2+}$. Esses menores alcances indicam menor continuidade espacial na área em estudo para esses dois atributos químicos; e

- A análise da variabilidade espacial dos atributos da fertilidade de Neossolo Quartzarênico Órtico típico em função da conversão do Cerrado em pastagem de Brachiaria brizantha cv. Marandu permitiu identificar zonas de fertilidade distintas e bem definidas. Desse modo, técnicas de manejo podem ser usadas para monitorar a fertilidade do solo e a qualidade ambiental.

\section{AGRADECIMENTOS}

Ao CNPq e Capes, pelas bolsas concedidas aos autores, e à Universidade Federal do Tocantins, pelo apoio.

\section{REFERÊNCIAS BIBLIOGRÁFICAS}

BERNOUX, M.; CERRI, C.C.; CERRI, C.E.P.; SIQUEIRA NETO, M.; METAY, A.; PERRIN, A.; SCOPEL, E.; BLAVET, D.; PICCOLO, M.C. Influence du semis direct avec couverture végétale sur la séquestration du carbone et l'érosion au Brésil. Bulletin du Réseau Erosion, v.23, p.323337, 2004.

CAMBARDELLA, C.A.; MOORMAN, T.B.; NOVAK, J.M.; PARKIN, T.B.; KARLEN, D.L.; TURCO, R.F.; KONOPKA, A.E. Field-scale variability of soil properties in Central Iowa Soils. Soil Science Society of America Journal., v.58, p.1501-1511, 1994.

CARNEIRO, M.A.C.; SOUZA, E.D.; REIS, E.F.;
PEREIRA, H.S.; AZEVEDO, R.W. Atributos físicos, químicos e biológicos de solo de cerrado sob diferentes sistemas de uso e manejo. Revista Brasileira de Ciência do Solo, Viçosa, v.33, n.1, p.147-157, 2009.

CARVALHO, J.R.P. de; SILVEIRA, P.M. da; VIEIRA, S.R. Geoestatística na determinação da variabilidade espacial de características químicas do solo sob diferentes preparos. Pesquisa Agropecuária Brasileira, Brasília, v.37, n.8, p.1151-1159, 2002.

CARVALHO, M. P.; TAKEDA, E.Y.; FREDDI, O.S. Variabilidade espacial de atributos de um solo sob videira em Vitória Brasil (SP). Revista Brasileira de Ciência do Solo, Viçosa, vol.27, n.4, p.695-703, 2003.

CASTRIGNANÒ, A.; GIUGLIARINI, L.; RISALITI, R.; MARTINELLI, N. Study of spatial relationships among some soil physicochemical properties of a field in central Italy using multivariate geostatistics. Geoderma, v.97, p.3960, 2000.

CAVALCANTE, E.G.S.; ALVES, M.C.; SOUZA, Z. M.; PEREIRA, G.T. Variabilidade espacial de atributos químicos do solo sob diferentes usos e manejos. Revista Brasileira de Ciência do Solo, Viçosa, v.31, n.6, p.1329-1339, 2007.

CFSEMG - COMISSÃO DE FERTILIDADE DO SOLO DO ESTADO DE MINAS GERAIS. Recomendações para o uso de corretivos e fertilizantes em Minas Gerais $-\mathbf{5}^{\mathbf{a}}$ Aproximação. Viçosa, 1999. 359p.

CORÁ, J.E.; ARAUJO, A.V.; PEREIRA, G.T.; BERALDO, J.M.G. Variabilidade espacial de atributos do solo para adoção do sistema de agricultura de precisão na cultura de cana-deaçúcar. Revista Brasileira de Ciência do Solo, Viçosa, v.28, n.6, p.1013-1021, 2004.

CORRÊA, A.N.; TAVARES, M.H.F.; URIBEOPAZO, M.A. Variabilidade espacial de atributos físicos do solo e seus efeitos sobre a produtividade 
do trigo. Semina: Ciências Agrárias. Londrina, v.30, n.1, p.81-94, 2009.

EMBRAPA - Empresa Brasileira de Pesquisa Agropecuária. Manual de análises de solo, planta e fertilizante. Brasília: Embrapa produção de informação, 1999. 412p.

Análise da informação pedológica da Região de Araguaína e Palmerantes-TO para fins de zoneamento agrícola. Planaltina: Embrapa produção de informação, 2005. 17p.

Sistema brasileiro de classificação de solos. Brasília: Embrapa produção de informação, 2006. 306p.

FENG, Q.; LIU, Y.; MIKAMI, M. Geostatistical analysis of soil moisture variability in grassland. Journal of Arid Environments, v.58, p.357-372, 2004.

FRAGA, V.S.; SALCEDO, I.H. Declines of organic nutrient pools in tropical semi-arid soils under subsistence farming. Soil Science Society of America Journal, Madison, v.68, n.1, p.215-224, 2004

GOLDEN SOFTWARE. Surfer for Windows version 8.0. Colorado: Golden, 2002.

GOMES, F.P.A Estatística Moderna na Pesquisa Agropecuária. Piracicaba: POTAFOS, 1984. $160 \mathrm{p}$.

GOMES, J.B.V.; BOLFE, E.L.; CURI, N.; FONTES, H.R. BARRETO, A.C.; VIANA, R.D. Variabilidade espacial de atributos de solos em unidades de manejo em área piloto de produção integrada de coco. Revista Brasileira de Ciência do Solo, Viçosa, v.32, n.6, p.2471-2482, 2008.

GOOVAERTS, P. Geostatistical tools for characterizing the spatial variability of microbiological and physico-chemical soil properties. Biology and Fertility of Soils, v.27, n.4, p.315-334, 1998.
GREGO, C.R.; VIEIRA, S.R. Variabilidade espacial de propriedades físicas do solo em uma parcela experimental. Revista Brasileira de Ciência do Solo, Viçosa, v.29, n.2, p.169-177, 2005.

ISAAKS, E.H.; SRIVASTAVA, R.M. An introduction to applied geoestatistics. New York: Oxford University, 1989. 561p.

LI, H.; LASCANO, R.J.; BOOKER, J.; WILSON, L.T.; BRONSON, K.F.; SEGARRA, E. State-space description of heterogeneity: water and nitrogen use in cotton. Soil Science Society of America Journal, Madison, v.66, n.2, p.585-595, 2002.

LITTLE, T.M. \& HILLS, F.J. Agricultural experimentation. New York, John Wiley \& Sons, 1978. 350p.

MACEDO, M.C.M. Pastagens no ecossistema cerrados: pesquisa para o desenvolvimento sustentável. In: Simpósio sobre pastagens nos ecossistemas brasileiros: pesquisas para o desenvolvimento sustentável, Brasília. 1995. Anais... Brasília, DF: Sociedade Brasileira de Zootecnia, 1995. p.28-62.

MACHADO, L.O.; LANA, A.M.Q.; LANA, R.M.Q.; GUIMARÃES, E.C.; FERREIRA, C. V. Variabilidade espacial de atributos químicos do solo em áreas sob sistema de plantio convencional. Revista Brasileira de Ciência do Solo, Viçosa, v.31, n.3, p.591-599, 2007.

OLIVEIRA, O.C.; OLIVEIRA, I.P.; ALVES, B.J.R.; URQUIAGA, S.; BODDEY, R.M. Chemical and biological indicators of decline/degradation of Brachiaria pasture in the Brazilian Cerrado. Agriculture, Ecosystem and Environment, v.103, n.2, p.289-300, 2004.

ROBERTSON, G.P. GS+: Geostatistics for the environmental sciences - GS+ User's guide. Plainwell, Gamma Design Soffware, 2008. 152p.

SANTOS, A.C.; SALCEDO, I.H.; CANDEIAS, A.L.B.; GALVÃO, S.R.S. Influência do uso e da 
posição do perfil no relevo na fertilidade de solos em áreas de encosta. Pesquisa Agropecuária Tropical. Goiânia, v.39, n.1, p.31-37, 2009.

SCHAFFRATH, V.R.; TORMENA, C.A.; FIDALSKI, J.; GONCALVES, A.C.A. Variabilidade e correlação espacial de propriedades físicas de solo sob plantio direto e preparo convencional. Revista Brasileira de Ciência do Solo, Viçosa, v.32, n.4, p.1369-1377, 2008.

SILVA, F.A.S. Software Assistat: Assistência Estatística. Versão 7.5 beta. Campina Grande: UAEG-CTRN-UFCG, 2008.

SILVA, V.R.; REICHERT, J.M.; STORCK, L.; FEIJO, S. Variabilidade espacial das características químicas do solo e produtividade de milho em um Argissolo Vermelho-Amarelo distrófico arênico. Revista Brasileira de Ciência do Solo, Viçosa. v.27, n.6, p.1013-1020, 2003.

SOUSA, D.M. \& LOBATO, E. Cerrado: Correção do solo e adubação. 2.ed. Brasília, Embrapa Informação Tecnológica, 2004. 416p.

SOUZA, G.S.; LIMA, J.S.S.; SILVA, S.A.; OLIVEIRA, R.B. Variabilidade espacial de atributos químicos em um Argissolo sob pastagem. Acta Scientiarum. Agronomy, v.30, n.4, p.589596, 2008.
SOUZA, L.S.; COGO, N.P.; VIEIRA, S.R. Variabilidade de propriedades físicas e químicas do solo em um pomar cítrico. Revista Brasileira de Ciência do Solo, Viçosa, v.21, p.367-372, 1997.

SOUZA, Z.M.; MARQUES JUNIOR, J.; PEREIRA, G.T.; MOREIRA, L.F. Variabilidade espacial do $\mathrm{pH}, \mathrm{Ca}, \mathrm{Mg}$ e V\% do solo em diferentes formas do relevo sob cultivo de cana-de-açúcar. Ciência Rural. Santa Maria, v.34, n.6, p.17631771, 2004.

TIESSEN, H.; SALCEDO, I.H.; SAMPAIO, E.V.S.B. Nutrient and soil organic matter dynamics under shifting cultivation in semi-arid northeastern Brazil. Agriculture,Ecosystems \& Environment, Amsterdam, v.38, n.3, p.139-151, 1992.

VIEIRA, S.R. Geoestatística em estudos de variabilidade espacial do solo. In: NOVAIS, R. F.; ALVAREZ, V.H.; SCHAEFER, C.E.G.R. (Ed.) Tópicos em ciência do solo. Viçosa: Sociedade Brasileira de Ciência do Solo, 2000. v.1, p.1-53.

VOLPE, E.; MARCHETTI, M.E.; MACEDO, M C.M.; ROSAJUNIOR, E.J. Renovação de Pastagem degradada com calagem, adubação e leguminosa consorciada em Neossolo Quartzarênico. Acta Scientiarum. Agronomy, v.30, n.1, p.131-138, 2008. 